\title{
Utilization of traditional Chinese medicine in the intensive care unit
}

\author{
Xia Zhang ${ }^{1,2,3 \dagger}$, Mingqi Wang ${ }^{1,2,3 \dagger}$, Wen Wang ${ }^{1,2,3}$, Ling Li $i^{1,2,3}$ and Xin Sun ${ }^{1,2,3^{*}}$
}

\begin{abstract}
Previous studies showed that traditional Chinese medicine (TCM) may be effective for patients with critical conditions. However, the extent to which TCM is used in intensive care units (ICUs) remains less investigated. This study aimed to investigate the utilization of TCM among ICU patients. Using a cross-sectional study design, we examined the use of TCMs among ICU patients. The data were from a well-established ICU registry from a large teaching hospital in west China. Our study found that TCM was widely used among ICU, in particular TCM injections and oral liquids. The use of TCM often differed by ICUs, and TCM injections and oral liquids were mostly used in neurological ICU, while Chinese herbal medicines (CHMs) were often used in general ICU. The use of TCM was also highly associated with patient characteristics. Patients with pancreatitis were administered with most TCM, patients with cerebrovascular disease with most TCM injections and those with chronic renal failure with most oral liquids. Future efforts should include generation of high-quality evidence guidelines about clinical effects of TCM interventions among ICU patients.
\end{abstract}

Keywords: Traditional Chinese medicine, Intensive care unit, Utilization

\section{Background}

Traditional Chinese medicine (TCM) is one of the most popular complementary and alternative medicine modalities worldwide [1]. Chinese governmental authorities have attached high importance to the development TCM and have issued 26 policies and measures from 2012 to 2019 [2]. These efforts were even strengthened in the past 2 years. As one of its targeted uses, TCM is often used among patients with critical conditions such as ischemic heart diseases and coronavirus disease 2019 (COVID-19) [3, 4]. Previous systematic reviews also suggested that TCM may be effective managing these patients [5-8]. However, the extent to which TCM is used among patients with critical conditions, particularly those at intensive care units (ICUs), is less investigated. The lack of clear understanding about the use of TCM

\footnotetext{
*Correspondence: sunxin@wchscu.cn

${ }^{+} X i a$ Zhang and Mingqi Wang contributed equally to this work

${ }^{1}$ Chinese Evidence-Based Medicine Center, West China Hospital, Sichuan University, 37 Guo Xue Xiang, Chengdu 610041, Sichuan, China

Full list of author information is available at the end of the article
}

has prevented better characterization of clinical values of TCM among these patients. Therefore, using a crosssectional study, we systematically investigated the pattern of using TCM among patients at ICUs.

\section{Main text}

This study was conducted using data from a large registry of 22,343 ICU patients from the West China Hospital (WCH), Sichuan University, a leading medical center in west China. The registry integrated multiple database systems, including ICU data, healthcare-associated infections at ICUs (ICU-HAI) and electronic medical records (EMRs). Details of this registry were published elsewhere and data in the registry had a high level of completeness and accuracy [9-11].

In this study, we included patients who were admitted to ICUs from April 1, 2015 to December 31, 2018. Patients were excluded if they met any of the following: younger than 18 years old; lack of critical information (e.g., date of birth, discharge diagnosis); and abnormal costs or length of stay at ICU (i.e., total cost equal to 0 or length of stay $>365$ days). Patient characteristics were

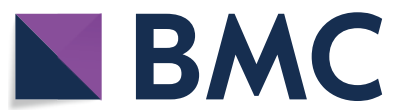

(c) The Author(s) 2021. Open Access This article is licensed under a Creative Commons Attribution 4.0 International License, which permits use, sharing, adaptation, distribution and reproduction in any medium or format, as long as you give appropriate credit to the original author(s) and the source, provide a link to the Creative Commons licence, and indicate if changes were made. The images or other third party material in this article are included in the article's Creative Commons licence, unless indicated otherwise in a credit line to the material. If material is not included in the article's Creative Commons licence and your intended use is not permitted by statutory regulation or exceeds the permitted use, you will need to obtain permission directly from the copyright holder. To view a copy of this licence, visit http://creativecommons.org/licenses/by/4.0/. The Creative Commons Public Domain Dedication waiver (http://creativeco mmons.org/publicdomain/zero/1.0/) applies to the data made available in this article, unless otherwise stated in a credit line to the data. 
extracted from the registry, including demographics, hospitalization at ICUs (admission and discharge date, ICU wards); prescription (drug names, drug types, dose, route, date of prescriptions); and diagnostic information (outpatient, admitting and discharge diagnosis). Patient comorbidities were identified according to the International Classification of Diseases, 10th edition (ICD-10). The completeness and accuracy of the ICD-10 were $99 \%$ and $88 \%$, respectively [9]. The information about TCM use was collected from ICU prescriptions which were documented in the EMRs. We established drug dictionary using drug codes provided by the hospital, which were previously validated [12] and contained information regarding drug name, route of administration, usage, and type of TCM.

Of the 22,343 patients, $6583(29.5 \%)$ were prescribed with TCM, including 5424 (24.3\%) using TCM injection, 1740 (7.8\%) using TCM oral liquid and 790 (3.5\%) using Chinese herbal medicine (CHM) (Additional file 1: Table S1). A total of 1881 patients were treated with multiple TCM injections and oral liquids, of whom 1336 (71.1\%) were treated with multiple TCM injections, including $1025(77.8 \%)$ receiving two TCM injections and $311(55.2 \%)$ receiving more than two TCM injections (Additional file 1: Table S2).

A total of 438 TCMs were used in the ICU. Among all TCM used, Bupleurum injection (13.5\%), Myrtol standardized enteric capsules (3.0\%) and Jiang Magnolia (3.3\%) were the most used TCM injection, oral liquid and CHM (Additional file 1: Table S3). The use of TCM prescriptions also differed by ICUs. While TCM injections and oral liquids were most frequently used in the neurological ICU (53.1\% and 13.5\%, respectively), and $\mathrm{CHM}$ were often used in the general ICU (7.2\%) (Additional file 1: Table S4).

The use of TCM interventions was associated with patient characteristics. Patients with pancreatitis (89.9\%) were the population who used the most used TCM interventions, patients with cerebrovascular disease (51.6\%) with the most TCM injections, and those with chronic renal failure (15.2\%) with the most oral liquids (Fig. 1). Across eight patient populations with different comorbidities, Bupleurum injection, Tanreqing injection and Myrtol standardized enteric capsules were the most used TCM injection and oral liquid (Additional file 1: Table S5).

Our study suggested that TCM was commonly used among ICU patients and TCM injections were more commonly used, particularly in patients at neurological ICU. Our study was consistent with previous publication that suggested the wide use of TCMs in patients with cerebrovascular disease [13]. The wide use of TCM injections was partly due to the nature of the ICU care; in addition, availability of reimbursement for these

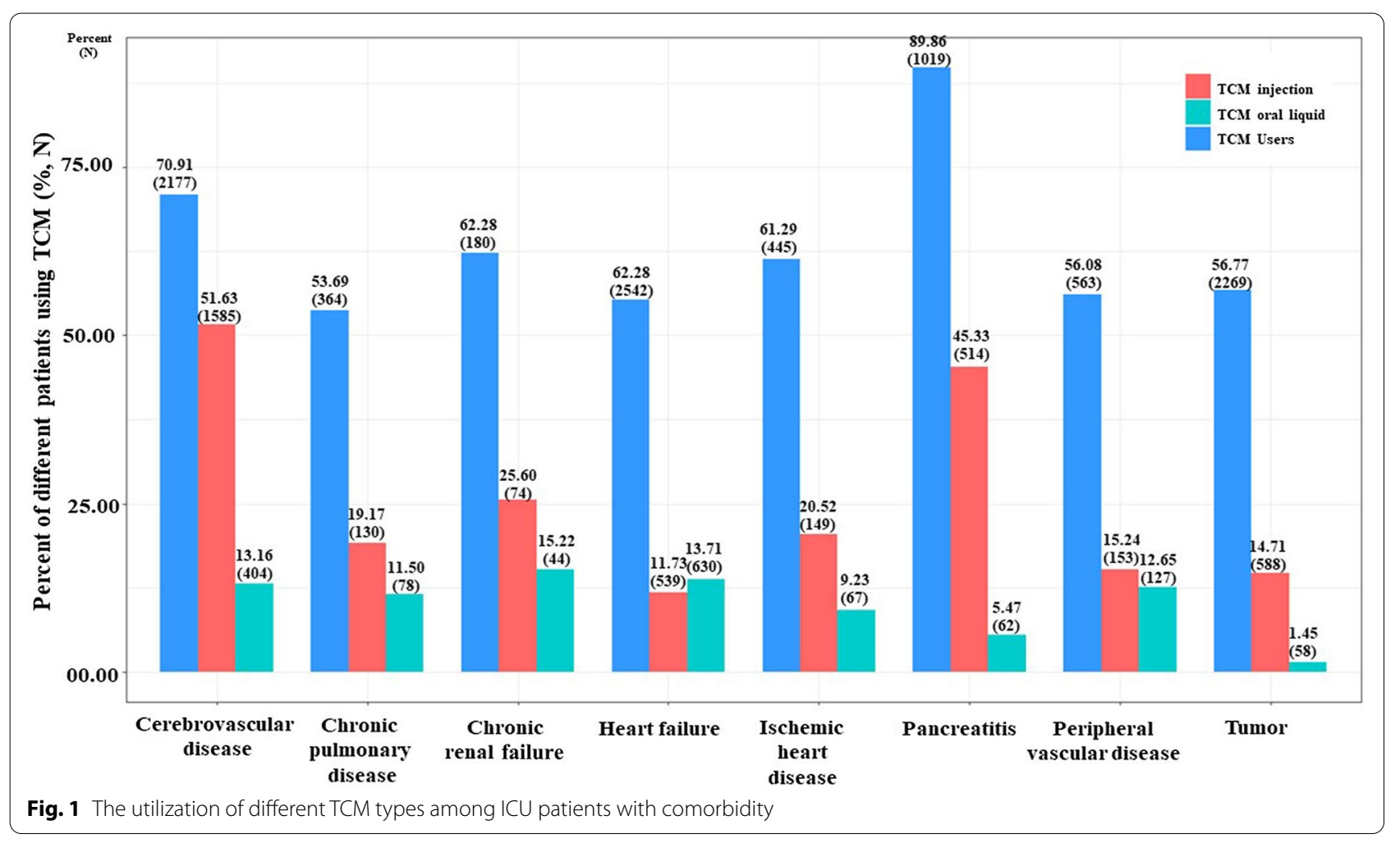


prescriptions may support their clinical use [14]. We also found that the use of TCM was often associated with patient characteristics. For example, TCMs were mostly used in patients with pancreatitis, which might be related to the published guidelines for pancreatitis treatment in China [15]. TCM injections were mostly used for patients with cerebrovascular diseases, likely due to their advantages in this patient population. Our finding was consistent with a previous study [16].

To the best of our knowledge, this was the first study that investigated the treatment patterns of TCMs among ICU patients. Our study included a large number of patients from a well-established registry. However, this study has a few limitations. Firstly, information regarding herbal formulas (multiherb products) was unavailable, for which we were unable to look into details about their uses. Secondly, our study was based on data from a single health care institution, which may limit the generalizability of findings. Nevertheless, it is the largest medical center in west China that has the largest ICU departments in the region. Thus, the findings may represent the treatment patterns from the west China region.

To further rationalize the use of TCM in ICU, more high-quality evidence about clinical effects of TCM is warranted. In particular, efforts are needed to further improve the quality of clinical studies about TCM in ICU, and trustworthy, normative and operationalizable guidelines of TCM in ICU that are based on systematic review evidence and GRADE approach should be developed. In addition, wider application of TCM in the ICU patient would also largely rely on healthcare policy. As such, industry standards and norms that meet the features of TCM interventions in the ICU should be also formulated.

\section{Conclusions}

Using data from a well-established registry, our study has clearly suggested that TCMs are commonly used among ICU patients in China. In particular, TCM injections and oral liquids are more often used than CHM. The use of TCM was also associated with patient characteristics and patients with pancreatitis were prescribed with most TCM. Future efforts should include systematic development of clinical evidence, guidelines and standards about clinical effects of TCM interventions in the ICU patients.

\footnotetext{
Abbreviations

CHM: Chinese herbal medicine; COVID-19: Coronavirus disease 2019; EMR: Electronic medical record; ICU: Intensive care unit; ICU-HAI: Healthcare-Associated Infections monitoring system in intensive care unit; ICD-10: International Classification of Diseases, 10th edition; NHC: National Health Commission; TCM: Traditional Chinese medicine; WCH: West China Hospital.
}

\section{Supplementary Information}

The online version contains supplementary material available at https://doi. org/10.1186/s13020-021-00496-1.

Additional file 1: Table S1. Demographic characteristics of user or nonuser of TCM. Table S2. The combinations use of TCM interventions among ICU patients. Table S3. The mostly used TCMs in the ICU. Table S4. The utilization of TCM among the ICU patients. Table S5. Mostly used TCM injections and TCM oral liquids among ICU patients with comorbidities.

\section{Acknowledgements}

The authors would like to thank Qiao He, Mei Liu, Peng Ji and Kang Zou for their helpful discussions on topics related to this work.

\section{Authors' contributions}

XS conceived and designed the study. XZ, MQW, WW, and LL, coordinated data collection. XZ, WW, and LL conducted the analyses. XZ and MQW wrote the manuscript. All co-authors critically revised the manuscript. All authors read and approved the final manuscript.

\section{Funding}

This study was supported by the National Key Research and Development Program of China (Grant No. 2019YFC1709804), the National Key Research and Development Program of China (Grant No. 2017YFC1700406), Sichuan Youth Science and Technology Innovation Research Team (Grant No. 2020JDTD0015), 1.3.5 project for disciplines of excellence, West China Hospital, Sichuan University (Grant No. ZYYC08003) and China Medical Board (Grant No. CMB19-324).

\section{Availability of data and materials}

The datasets used and analysed during the current study are available from the corresponding author upon reasonable request.

\section{Declarations}

Ethics approval and consent to participate

This study was approved by the Ethical Committee of West China Hospital in 2018 (WCH2018-409), and the need for patient consent was waived.

Consent for publication

The authors give full consent to publish.

\section{Competing interests}

The authors declare that they have no competing interests.

\section{Author details}

${ }^{1}$ Chinese Evidence-Based Medicine Center, West China Hospital, Sichuan University, 37 Guo Xue Xiang, Chengdu 610041, Sichuan, China. ${ }^{2}$ NMPA Key Laboratory for Real World Data Research and Evaluation in Hainan, Chengdu, China. ${ }^{3}$ Sichuan Center of Technology Innovation for Real World Data, Chengdu, China.

Received: 1 June 2021 Accepted: 13 August 2021

Published online: 23 August 2021

\section{References}

1. Williamson EM, Lorenc A, Booker A, Robinson N. The rise of traditional Chinese medicine and its materia medica: a comparison of the frequency and safety of materials and species used in Europe and China. J Ethnopharmacol. 2013;149(2):453-62.

2. Wang WY, Zhou H, Wang YF, Sang BS, Liu L. Current policies and measures on the development of traditional chinese medicine in China. Pharmacol Res. 2021;163:105187

3. Lu C, Lu P, Chen P. Utilization trends in traditional Chinese medicine for acute myocardial infarction. J Ethnopharmacol. 2019;241:112010. 
4. Huang YF, Bai C, He F, Xie Y, Zhou H. Review on the potential action mechanisms of Chinese medicines in treating coronavirus disease 2019 (COVID-19). Pharmacol Res. 2020;158:104939.

5. Fan TT, Cheng BL, Fang XM, Chen YC, Su F. Application of Chinese medicine in the management of critical conditions: a review on sepsis. Am J Chin Med. 2020;48(6):1315-30.

6. Wu JR, Zhang XM, Zhang B. Danhong injection in the treatment of acute coronary syndrome: a systematic review and meta-analysis. Am J Chin Med. 2015:43(2):199-214.

7. Liu AJ, Li JH, Li HQ, Fu DL, Lu L, Bian ZX, et al. Electroacupuncture for acute ischemic stroke: a meta-analysis of randomized controlled trials. Am J Chin Med. 2015;43(8):1541-66.

8. Zhou Y, Wang L, Huang X, Li H, Xiong Y. Add-on effect of crude rhubarb to somatostatin for acute pancreatitis: a meta-analysis of randomized controlled trials. J Ethnopharmacol. 2016;194:495-505.

9. Wang W, Zhu S, He Q, Zhang R, Kang Y, Wang M, et al. Developing a registry of healthcare-associated infections at intensive care units in West China: study rationale and patient characteristics. Clin Epidemiol. 2019;11:1035-45.

10. He Q, Wang W, Zhu S, Wang M, Kang Y, Zhang R, et al. The epidemiology and clinical outcomes of ventilator-associated events among 20,769 mechanically ventilated patients at intensive care units: an observational study. Crit Care. 2021;25(1):44
11. Zhu S, Kang Y, Wang W, Cai L, Sun X, Zong Z. The clinical impacts and risk factors for non-central line-associated bloodstream infection in 5046 intensive care unit patients: an observational study based on electronic medical records. Crit Care. 2019;23(1):52.

12. Wang W, Liu Y, Yu C, Tan J, Xiong W, Dong D, et al. Cefoperazone-sulbactam and risk of coagulation disorders or bleeding: a retrospective cohort study. Expert Opin Drug Saf. 2020;19(3):339-47.

13. Zhang JH, Zhu Y, Fan XH, Zhang BL. Efficacy-oriented compatibility for component-based Chinese medicine. Acta Pharmacol Sin. 2015;36(6):654-8

14. Xiao Y, Zhao K, Bishai DM, Peters DH. Essential drugs policy in three rural counties in China: what does a complexity lens add? Soc Sci Med. 1982;2013(93):220-8

15. Branch of Gastrointestinal Diseases CAoCM. Expert consensus on TCM diagnosis and treatment of acute pancreatitis (2017). J Clin Hepatol. 2017;33:2052-7.

16. Wu D, Wang LC. Application of traditional Chinese medicine injection in cerebrovascular diseases. Med Inf. 2015:28:354.

\section{Publisher's Note}

Springer Nature remains neutral with regard to jurisdictional claims in published maps and institutional affiliations.
Ready to submit your research? Choose BMC and benefit from:

- fast, convenient online submission

- thorough peer review by experienced researchers in your field

- rapid publication on acceptance

- support for research data, including large and complex data types

- gold Open Access which fosters wider collaboration and increased citations

- maximum visibility for your research: over $100 \mathrm{M}$ website views per year

At BMC, research is always in progress.

Learn more biomedcentral.com/submissions 